\title{
Numerical Simulation of In Situ Combustion of Oil Shale
}

\author{
Huan Zheng, Weiping Shi, Dali Ding, and Chuangye Zhang \\ College of Mathematics, Jilin University, Changchun 130012, China \\ Correspondence should be addressed to Weiping Shi; shiwp@jlu.edu.cn
}

Received 2 March 2017; Accepted 17 May 2017; Published 8 June 2017

Academic Editor: Micol Todesco

Copyright (C) 2017 Huan Zheng et al. This is an open access article distributed under the Creative Commons Attribution License, which permits unrestricted use, distribution, and reproduction in any medium, provided the original work is properly cited.

\begin{abstract}
This paper analyzes the process of in situ combustion of oil shale, taking into account the transport and chemical reaction of various components in porous reservoirs. The physical model is presented, including the mass and energy conservation equations and Darcy's law. The oxidation reactions of oil shale combustion are expressed by adding source terms in the conservation equations. The reaction rate of oxidation satisfies the Arrhenius law. A numerical method is established for calculating in situ combustion, which is simulated numerically, and the results are compared with the available experiment. The profiles of temperature and volume fraction of a few components are presented. The temperature contours show the temperature variation in the combustion tube. It is found that as combustion reaction occurs in the tube, the concentration of oxygen decreases rapidly, while the concentration of carbon dioxide and carbon monoxide increases contrarily. Besides, the combustion front velocity is consistent with the experimental value. Effects of gas injection rate, permeability of the reservoir, initial oil content, and injected oxygen content on the ISC process were investigated in this study. Varying gas injection rate and oxygen content is important in the field test of ISC.
\end{abstract}

\section{Introduction}

Oil shales are organic-rich sedimentary rocks that contain significant amounts of kerogen [1]. Kerogen is regarded as a complex organic mixture and can be pyrolysed to produce oil and gas [2,3]. Deposits of oil shale have been found in 27 countries worldwide [4]. Oil shale becomes an important alternative energy due to its huge reserves [5]. It is quite possible to satisfy the future oil requirement. Upon being heated, kerogen in oil shale can be converted to oil and gas. The heating process is called pyrolysis or retorting. Two primary types of retorting processes have been developed [5]: surface retorting and in situ conversion.

In situ processes introduce heat to the oil shale which is still embedded in its natural geological formation $[6,7]$. One of the in situ methods is the in situ combustion (ISC), which comprises three steps: conduction heating, hot gas injection, and in situ combustion $[8,9]$. In the step of conduction heating, oil shale is heated. In the second step, hot gas is injected into the oil shale layer and the surrounding cool oil shale would be heated. In situ combustion is the process whereby hot air is injected into the oil shale layer in order to react with the organic component (kerogen). The combustion reaction produces enough heat to propagate a combustion wave leading to cracking and vaporization of lighter components [10]. The pyrolysis of oil shale is triggered by the combustion reactions in the absence of an extra heat supply. Shale oil is obtained through the pyrolysis process.

ISC has been considered as a clean method for enhanced oil recovery of heavy oil which has high viscosity [1113]. The principle of in situ combustion is generating heat to pyrolysis itself by injecting hot air. There have been a number of previous studies that were relevant to thermal and combustion waves for oil recovery. Several contributions have already been reported, such as the structure of the combustion wave, the wave propagation, and the sensitivity analysis of parameters.

Mailybaev et al. investigated the ISC process of oil and classified the structure of the combustion waves through the ratio of the oxygen injection rate and the coke formation rate [14]. Their results on the positions of the hot zone were different in the combustion waves: reaction-leading and reaction-trailing wave structures.

The phase behavior, permeability, and pressure play significant roles in the thermal and combustion waves. The phase behavior effects in enhanced oil recovery through ISC were investigated by Srinivasareddy and Kumar [11]. Gargar et al. proved that the injected air at medium pressures is better 


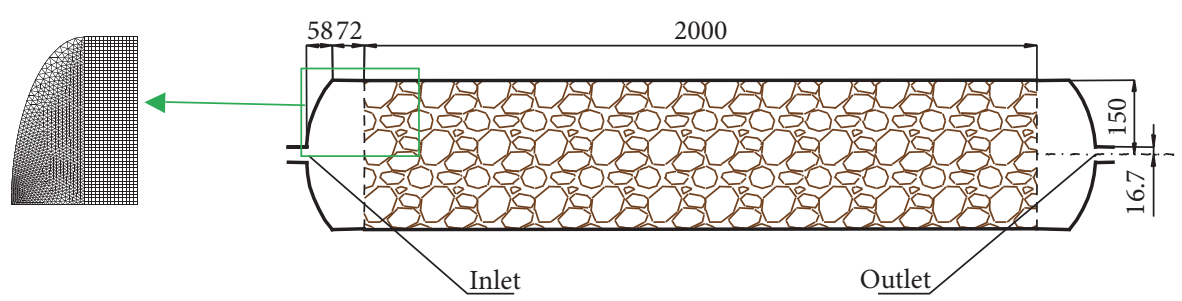

FIgURE 1: Combustion tube (unit: $\mathrm{mm}$ ) and local mesh.

than high pressures for light oil combustion [15], because of the shallower depths.

There are series of chemical reactions during the ISC process which are more complex than coal combustion [16]. Lapene et al. found a simplified chemical model for oil shale combustion in a fixed bed. The simple chemical model gave the same results as the experiment they did.

Although laboratory experiment has a better understanding on the combustion process, the complex reactive heat and mass transportation of oil shale make the field scale development of ISC even harder [15]. Numerical simulation of ISC for oil shale can describe coupled heat and mass transport in the porous medium, which can be treated as a scientific guidance for field tests. The temperature of oil shale and the concentration of carbon dioxide and carbon monoxide in the reservoir can be achieved.

This study focuses on the numerical simulation of in situ combustion of oil shale. A fully coupled mathematical model is presented to describe the chemical reactions and mass and heat transport in oil shale reservoir. As a numerical test, the combustion in a tube is simulated. At present, the computational fluid dynamic software FLUENT does not have the capability to model the in situ combustion of oil shale. Therefore we developed the comprehensive User's Defined Functions (UDFs) to calculate the multiphase flows of combustion. The UDFs are implanted in FLUENT. They extend the capability of FLUENT and provide a feasible tool for simulating in situ combustion. The numerical results are compared with the available experimental measurements. In order to assess the performance of the ISC method, several key parameters, gas injection rate, permeability of the reservoir, initial oil content, and injected oxygen content, were investigated.

\section{Model and Methods}

\subsection{Numerical Test}

2.1.1. Combustion Tube Experiment. The numerical test is a simulation of oil shale combustion in a stainless-steel tube. The scheme of the combustion tube is based on the experiment of [5], which is shown in Figure 1. It is a horizontal cylindrical reactor chamber with an internal radius of $150 \mathrm{~mm}$ and length of $2260 \mathrm{~mm}$ [5]. The size of the combustion tube is large enough for the in situ combustion of oil shale. A sustained and stable ISC process was obtained in the experiment of [5]. The combustion tube is covered with an insulation jacket to minimize heat losses, and the convection in the horizontal direction is much stronger than that in the vertical direction. Thus, the heat losses were ignored in this study. At the inlet in the left of Figure 1, there are connections for pure nitrogen and pure oxygen injections separately. At the outlet in the right, there is a connection for production of fluids and a regulator to adjust the background pressure. Oil shale blocks are stacked into a $2 \mathrm{~m}$ long region in the combustion tube [5]. There are two buffer zones of gas flow connecting the inlet and outlet in the combustion tube. At the inlet of the combustion tube, gas reaches the buffer zone firstly, where the velocity reduced greatly. A part of the simulated model's grid was shown in Figure 1. In the horizontal section, the size of the grid is consistent. And, like the symmetry of the model, the mesh of other parts can be known.

2.1.2. Experimental Process. At the beginning of the process, the temperature of oil shale was $291 \mathrm{~K}$. Pure hot nitrogen was injected into the tube continuously to preheat oil shale and avoid oxidation by acquiring the ambience of scarce oxygen. Once the temperature rose above $400 \mathrm{~K}$, the nitrogen injection was stopped, and air injection $\left(79 \% \mathrm{~N}_{2}, 21 \% \mathrm{O}_{2}\right.$ which was controlled by the inlet valve) was started. Hot air of $733 \mathrm{~K}$ was injected into the tube through the inlet (as shown in Figure 1) at a steady flow rate of $4.0 \mathrm{~m}^{3} / \mathrm{h}$ during the experiment. At this time the igniter in the tube was turned on. Combustion reactions occurred several minutes later and the combustion front went toward the outlet. When the combustion front approached the end of the tube, we stopped the experiment.

2.2. Governing Equations. This research was performed to simulate reacting multiphase flow in porous media. A coupled heat and mass transport model was considered. The governing equations used to solve the multiphase flows during the ISC process are outlined in this section. Assume that, during the combustion process, kerogen is considered to be immobile [11].

As to gaseous phases, the mass conservation equation for the mixture is

$$
\frac{\partial\left(\rho_{m} \varphi\right)}{\partial t}+\nabla \cdot\left(\rho_{m} \vec{u}_{m}\right)=\dot{m}_{m}
$$

where $\varphi$ is the porosity of the porous medium, $\dot{m}_{m}$ is the mass source term in $\mathrm{kg} / \mathrm{m}^{3} / \mathrm{s}$ (the expression is shown in the 
next section), and $\rho_{m}, u_{m}$ are the density and velocity of the gaseous mixture, respectively. Their expressions are

$$
\begin{aligned}
\rho_{m} & =\sum_{i} Y_{i} \rho_{i}, \\
\vec{u}_{m} & =\frac{\sum_{i} Y_{i} \rho_{i} \vec{u}_{i}}{\rho_{m}} .
\end{aligned}
$$

The subscript $i$ denotes different phases. Here $i=1,2,3,4$ indicate $\mathrm{O}_{2}, \mathrm{CO}_{2}, \mathrm{CO}$, and $\mathrm{N}_{2}$, respectively, where $\rho_{i}$ denotes the density for phase $i$ and $Y_{i}$ is the mole fraction of phase $i$ within the formation.

The mass conservation equation of each gaseous phase is

$$
\frac{\partial\left(\rho_{i} \varphi Y_{i}\right)}{\partial t}+\nabla \cdot\left(Y_{i} \rho_{i} \vec{u}_{i}\right)=\dot{m}_{i}
$$

where $\dot{m}_{i}$ is the mass source term of phase $i$ in $\mathrm{kg} / \mathrm{m}^{3} / \mathrm{s}$. For the mole fractions $Y_{i}$ of gaseous phases, the following equality holds:

$$
\sum_{i} Y_{i}=1
$$

The velocity of gas flow in the oil shale zone satisfies Darcy's law:

$$
u_{i}=-\frac{k_{0} k_{r i}}{\mu_{i}}(\nabla P-\rho g \nabla z),
$$

where $k_{0}$ is the absolute permeability of the porous medium, $k_{r i}$ is the relative permeability of phase $i, \mu_{i}$ is the viscosity of phase $i$, and $P$ represents phase pressure which are the same for different phases here. The gravitational effects are ignored due to the small size in the vertical direction in the laboratory experiments. So the second term on the right hand side of (5) is ignored in this study.

We assume that the solid and fluid are in local thermal equilibrium, so they have the same temperature. Convection plays a dominant role in heat transfer due to the continuous gas injection. The energy conservation equation for the solid and gaseous phases is given by

$$
\begin{aligned}
\frac{\partial}{\partial t}( & \left.(1-\varphi) \rho_{R} c_{R} T+\varphi \sum_{i=1}^{n} Y_{i} \rho_{i} c_{i} T\right)+\nabla \\
& \sum_{i=1}^{n} Y_{i} \vec{u}_{i}\left(\rho_{i} c_{i} T+p\right)=\nabla\left(k_{\mathrm{eff}} \nabla T\right)+\dot{Q},
\end{aligned}
$$

where $\rho_{R}$ is the density of the oil shale, $k_{\text {eff }}$ is the effective conductivity, $c_{R}, c_{i}$ are the specific heat capacity of the oil shale and gaseous phase $i$, respectively, and $\dot{Q}$ is the heat source term due to the chemical reactions. The expression of $\dot{Q}$ is in the next section.

2.3. Chemical Reaction. In situ combustion of oil shale in porous media is a complicated reaction, which follows series of decomposition and synthesis reactions occurring in a wide range of temperatures. We consider a reaction scheme comprising pyrolysis and combustion. The kerogen is converted into shale oil, gas, and coke at certain temperature due to the pyrolysis process. The pyrolysis process can be written as follows $[17,18]$ :

$$
\text { Kerogen } \longrightarrow \text { oil + gas + coke, }
$$

where coke represents the solid residual of kerogen pyrolysis. The combustion of coke produces considerable amounts of heat in the ISC process. Thus, the pyrolysis of kerogen can occur spontaneously in the absence of extra heat supply.

The inorganic decomposition reactions can be ignored due to the high temperature needed to activate them [10]. Thus in the combustion of oil shale, inorganic decomposition is neglected. As hot air is injected into the reservoir of oil shale, oxygen reacts with kerogen several minutes later; a series of reactions occur. Due to the complex combustion reactions, the numerical simulation is very difficult. Thus the complex oxidation reactions are simplified, which can correctly match the experimental results [16].

The simplified reactions are described by the following equations:

$$
\begin{gathered}
\mathrm{C}+\mathrm{O}_{2} \longrightarrow \mathrm{CO}_{2}, \\
\mathrm{C}+\frac{1}{2} \mathrm{O}_{2} \longrightarrow \mathrm{CO},
\end{gathered}
$$

where $C$ in reactions (8) and (9) represents the coke, which is regarded as fuel for the combustion process.

Under the chemical reaction equilibrium conditions, considering the number of moles of each component [19], the mass source terms in (3) are, respectively,

$$
\begin{aligned}
\dot{m}_{\mathrm{CO}_{2}} & =-\frac{M_{\mathrm{CO}_{2}}}{M_{\mathrm{C}}} \dot{m}_{\mathrm{C} 1}, \\
\dot{m}_{\mathrm{CO}} & =-\frac{M_{\mathrm{CO}}}{M_{\mathrm{C}}} \dot{m}_{\mathrm{C} 2}, \\
\dot{m}_{\mathrm{O}_{2}} & =-\frac{M_{\mathrm{O}_{2}}}{M_{\mathrm{CO}_{2}}} \dot{m}_{\mathrm{CO}_{2}}-\frac{1}{2} \frac{M_{\mathrm{O}_{2}}}{M_{\mathrm{CO}}} \dot{m}_{\mathrm{CO}},
\end{aligned}
$$

where $M_{\mathrm{CO}_{2}}, M_{\mathrm{CO}}, M_{\mathrm{C}}$, and $M_{\mathrm{O}_{2}}[\mathrm{~kg} / \mathrm{kmol}]$ are molecular weights of $\mathrm{CO}_{2}, \mathrm{CO}, \mathrm{C}$, and $\mathrm{O}_{2}$, respectively. $\dot{m}_{\mathrm{O}_{2}}, \dot{m}_{\mathrm{CO}}$, and $\dot{m}_{\mathrm{CO}_{2}}\left[\mathrm{~kg} / \mathrm{m}^{3} / \mathrm{s}\right]$ are the reaction rates of $\mathrm{O}_{2}, \mathrm{CO}$, and $\mathrm{CO}_{2}$, respectively. $\dot{m}_{\mathrm{C} 1}, \dot{m}_{\mathrm{C} 2}$ are the reaction rates of carbon in chemical reactions (8) and (9), respectively.

Therefore, the moles of carbon play a vital role in our calculation. The change of carbon chemical reaction rate determines the concentration variation of each component and the total heat generation.

In this study, the temperatures of oil shale and gas are equal (local thermal equilibrium) [20]. Heat losses are neglected. According to Arrhenius law, the reaction rate of carbon is expressed as

$$
\dot{m}_{\mathrm{cl}} \equiv \frac{d m_{\mathrm{c} 1}}{d t}=k_{d} Y_{\mathrm{O}_{2}} n_{\mathrm{c}} \exp \left(-\frac{E_{\mathrm{C}}}{R T}\right),
$$

where $k_{d}[1 / \mathrm{s}]$ is a constant, denoting the preexponential factor. $Y_{\mathrm{O}_{2}}$ and $n_{\mathrm{c}}\left[\mathrm{kg} / \mathrm{m}^{3}\right]$ represent mole fraction of oxygen 
TABLE 1: Parameters of oil shale and experimental conditions.

\begin{tabular}{lccc}
\hline Symbol & Property & Value & Unit \\
\hline$\varphi$ & Porosity & 0.5 & Dimensionless \\
$\rho_{R}$ & Oil shale density & 1700 & $\mathrm{~kg} / \mathrm{m}^{3}$ \\
$c_{R}$ & Capacity of oil shale & 1010 & $\mathrm{~J} / \mathrm{kg} \mathrm{K}$ \\
$k_{\text {eff }}$ & Effective conductivity & 1.88 & $\mathrm{w} / \mathrm{m} \mathrm{K}$ \\
$q_{\mathrm{CO}}$ & Reaction heat & $1.23 \times 10^{5}$ & $\mathrm{~J} / \mathrm{kg}$ \\
$q_{\mathrm{CO} 2}$ & Reaction heat & $4.08 \times 10^{5}$ & $\mathrm{~J} / \mathrm{kg}$ \\
$k_{d}$ & Preexponential factor & $1.0 \times 10^{9}$ & $1 / \mathrm{s}$ \\
$E_{\mathrm{c}}$ & Activation energy & $1.6 \times 10^{5}$ & $\mathrm{~J} / \mathrm{mol}$ \\
$\beta$ & Proportion of carbon consumption & 0.7709 & $\mathrm{Dimensionless}$ \\
$u_{\text {inj }}$ & Velocity of inlet & 1.273 & $\mathrm{~m} / \mathrm{s}$ \\
$M_{\mathrm{O} 2}$ & Molecular weight $\left(\mathrm{O}_{2}\right)$ & 32 & $\mathrm{~kg} / \mathrm{kmol}$ \\
$M_{\mathrm{CO} 2}$ & Molecular weight $\left(\mathrm{CO} \mathrm{O}_{2}\right)$ & 44 & $\mathrm{~kg} / \mathrm{kmol}$ \\
$M_{\mathrm{CO}}$ & Molecular weight $(\mathrm{CO})$ & 28 & $\mathrm{~kg} / \mathrm{kmol}$ \\
$M_{\mathrm{C}}$ & Molecular weight $(\mathrm{C})$ & 12 & $\mathrm{~K}$ \\
$T_{0}$ & The initial temperature & 400 & \\
$T_{\text {inj }}$ & Temperature of inlet air & 733 & $\mathrm{~K}$ \\
\hline
\end{tabular}

and concentration of carbon, respectively. $E_{C}$ is the activation energy of the reaction, $R$ is the ideal gas constant, and $T$ is the temperature.

We introduce a parameter $\beta$ to represent the proportion of carbon consumption in reaction (8) to the total amount of carbon consumption in both reactions (8) and (9); $\beta$ can be introduced as

$$
\beta=\frac{\dot{m}_{\mathrm{C} 1}}{\dot{m}_{\mathrm{C} 1}+\dot{m}_{\mathrm{C} 2}}
$$

The heat source term $\dot{Q}$ in (6) is described as follows:

$$
\begin{aligned}
\dot{\mathrm{Q}} & =\dot{\mathrm{Q}}_{\mathrm{CO}_{2}}+\dot{\mathrm{Q}}_{\mathrm{CO}}, \\
\dot{\mathrm{Q}}_{\mathrm{CO}_{2}} & =q_{\mathrm{CO}_{2}} \frac{M_{\mathrm{CO}_{2}}}{M_{\mathrm{C}}} \dot{m}_{\mathrm{C} 1}, \\
\dot{\mathrm{Q}}_{\mathrm{CO}} & =q_{\mathrm{CO}} \frac{M_{\mathrm{CO}}}{M_{\mathrm{C}}} \dot{m}_{\mathrm{C} 1},
\end{aligned}
$$

where $q_{\mathrm{CO}_{2}}, q_{\mathrm{CO}}$ denote the heat generation of reactions (8) and (9), respectively. UDFs were developed to simulate the chemical reactions including the reaction rate of each phase and amount of heat generation. Actually, the UDFs of $\dot{m}_{i}(i=$ $1,2,3,4)$ and $\dot{Q}$ were composed to represent the source terms in the conservation equations (3) and (6).

2.3.1. Initial and Boundary Conditions. The Initial conditions in combustion tube are

$$
\begin{aligned}
T & =T_{0}, \\
Y_{\mathrm{O}_{2}} & =0, \\
Y_{\mathrm{N}_{2}} & =1,
\end{aligned}
$$

where $Y_{\mathrm{O}_{2}}$ and $Y_{\mathrm{N}_{2}}$ are the mole fraction of $\mathrm{O}_{2}$ and $\mathrm{N}_{2}$, respectively, and $T_{0}$ is the initial temperature of the combustion tube. Due to the back pressure regulator, the gas injection rate was stabilized during combustion process. The boundary conditions at the inlet are

$$
\begin{aligned}
T & =T_{\text {in } j,}, \\
Y_{\mathrm{O}_{2}} & =0.21, \\
Y_{\mathrm{N}_{2}} & =0.79, \\
u_{\mathrm{in}} & =u_{\mathrm{in} j},
\end{aligned}
$$

where $u_{\text {in }}$ is the inlet velocity. The boundary conditions at the outlet are

$$
\begin{aligned}
\frac{\partial T}{\partial x} & =0, \\
\frac{\partial Y_{\mathrm{N}_{2}}}{\partial x} & =0, \\
\frac{\partial Y_{\mathrm{O}_{2}}}{\partial x} & =0, \\
P & =P_{\text {outlet }} .
\end{aligned}
$$

Side wall of combustion tube is thermally insulated. The above information was related to our base case. The values of parameters used in present study are listed in Table 1.

\section{Results and Discussion}

In this study, we investigate the in situ combustion process of oil shale in the combustion tube. Additionally, the impact of gas injection rate, permeability of the reservoir, initial oil content, and injected oxygen content was analyzed. The results for base case and other cases of the simulation are given in the following. 


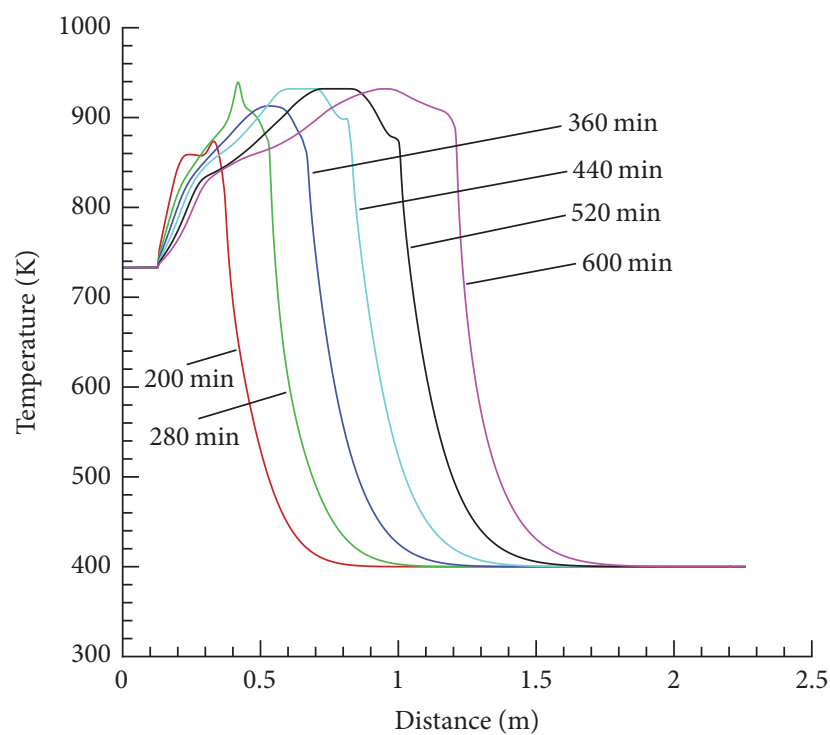

FIGURE 2: The temperature profiles of the oil shale at different times.

3.1. Simulation Model: Base Case. Figure 2 shows the temperature profiles of oil shale in the combustion tube at different times. We notice that the temperatures begin to rise steeply and then reach their maximum values. Finally, they drop to the temperature value of the inlet gas gradually. Different from other temperature profiles, there is a summit at $280 \mathrm{~min}$. The peak value appears due to the fact that the oxidation reactions occur quickly, heat is released intensely at the back of thermal front, and the combustion zone is of a small size at $280 \mathrm{~min}$. With the duration of oxidation reactions, the width of the combustion zone increases. Thus, the summit of temperature disappears. As the combustion going on, temperature profiles become smooth as shown in Figure 2.

The frontal locations of oil shale combustion are shown in Figure 3. The frontal moving velocity is derived from Figure 3; the velocity is $0.2114 \mathrm{~cm} / \mathrm{min}$ which fairly matches the experiment of Kök as $0.2333 \mathrm{~cm} / \mathrm{min}$ [21]. The result shows that the combustion front propagates in the tube at a constant velocity under the condition of constant gas injection rate throughout the runs.

Figure 4 presents the mole fraction of oxygen and temperature profile in the combustion tube at $360 \mathrm{~min}$. The correlation between combustion and oxygen consumption is displayed obviously in Figure 4. The mole fraction of oxygen decreased in the position of high temperature zone. It presents that large amounts of oxygen were consumed because of the combustion reactions, and a steep decrease of oxygen mole fraction was obtained due to the oxidation reactions of the coke. A similar result was obtained in [22].

The temperature contours in the combustion tube at different times are shown in Figure 5. The temperature increase of oil shale was mainly due to the chemical reactions. As shown in Figure 5(f), the contours demonstrate three zones of the ISC process: the spent shale zone, combustion zone, and the virgin oil shale zone. In the combustion zone, abundant heat is released by the combustion reactions, and temperature

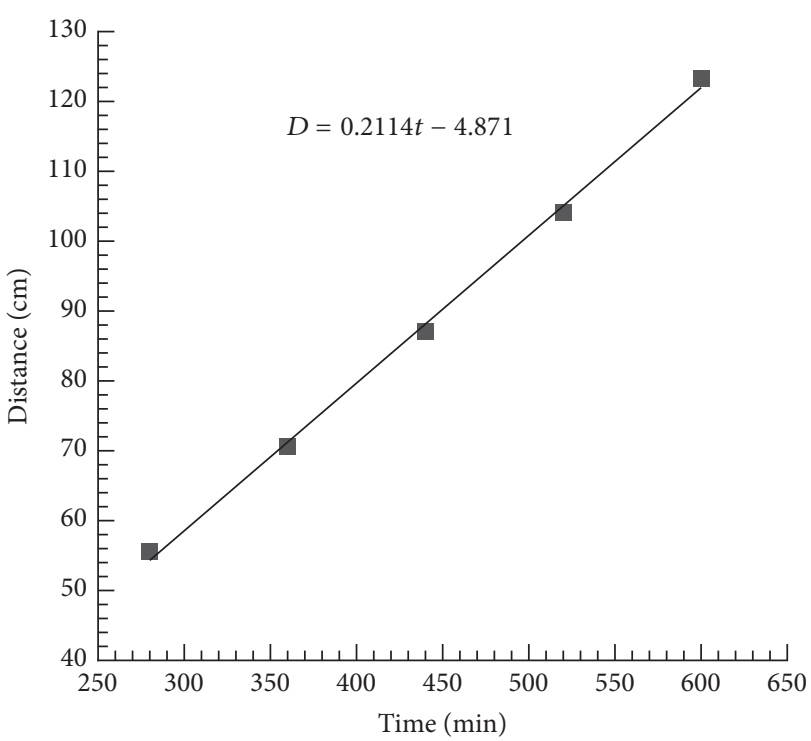

FIGURE 3: Locations of the fronts.

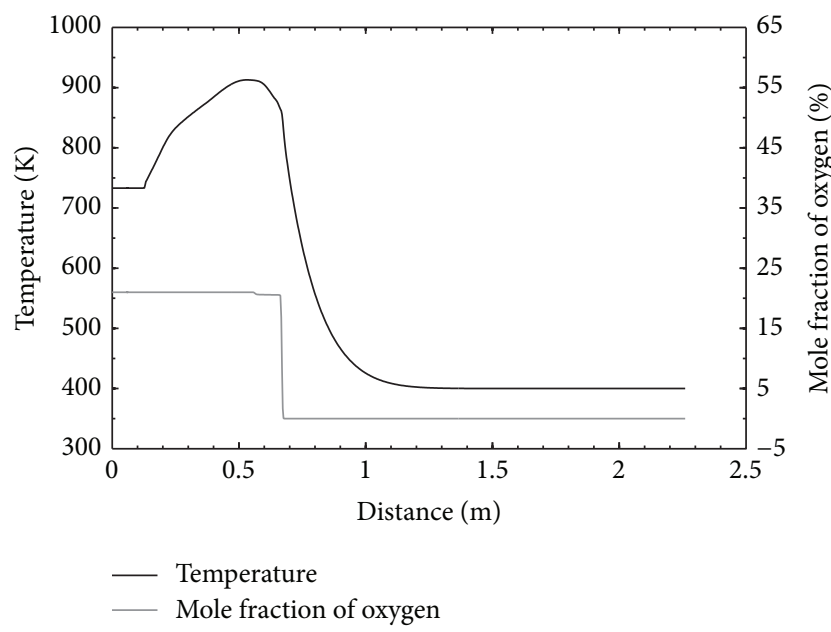

Figure 4: Temperature profile and volume fraction of oxygen at $360 \mathrm{~min}$.

reaches the peak. The thickness of the combustion zone is increasing with time due to the fact that the thermal front moving toward the outlet continuously and oil shale behind the front cannot cool quickly. Thus, the increasing rate of the thickness is related to the thermal front moving speed and the intensity of heat transfer at the back of thermal front.

3.2. Parameter Sensitivity. The sensitivity of numerical solutions to variations of 4 parameters is investigated. They are the gas injection rate, permeability of reservoir, initial oil content, and the injected oxygen content.

3.2.1. Effect of Gas Injection Rate. The gas injection rate significantly affects the ISC process. To investigate the effect of gas injection rate on the ISC process, three cases of different injection rates $\left(4.0 \mathrm{~m}^{3} / \mathrm{h}, 3.14 \mathrm{~m}^{3} / \mathrm{h}\right.$, and $\left.2.0 \mathrm{~m}^{3} / \mathrm{h}\right)$ 




(a) $t=200 \mathrm{~min}$
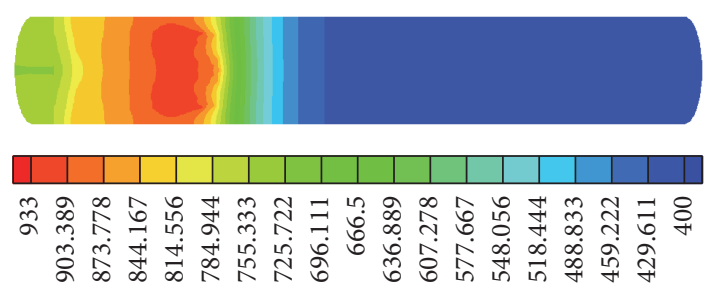

Temperature (K)

(c) $t=360 \mathrm{~min}$
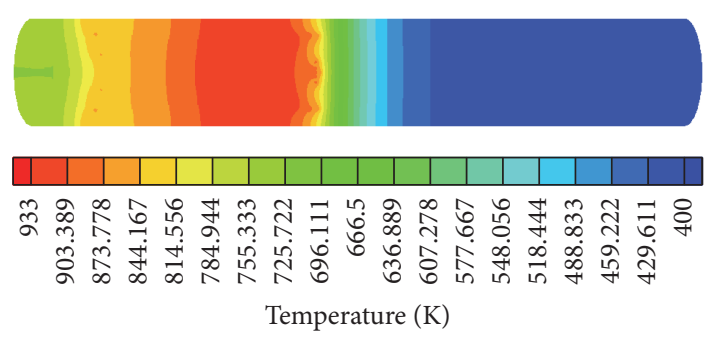

(e) $t=520 \mathrm{~min}$





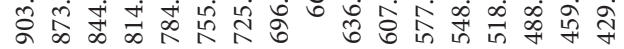
Temperature (K)

(b) $t=280 \mathrm{~min}$

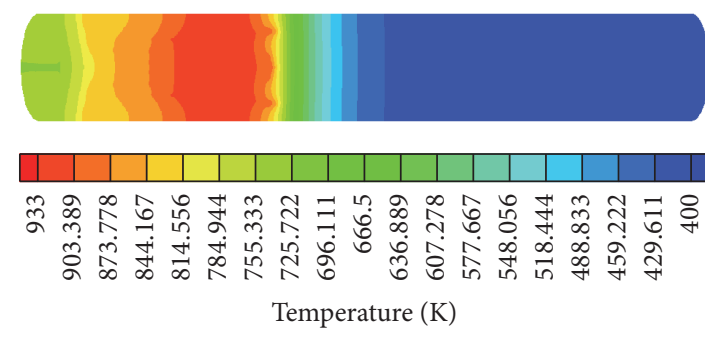

(d) $t=440 \mathrm{~min}$

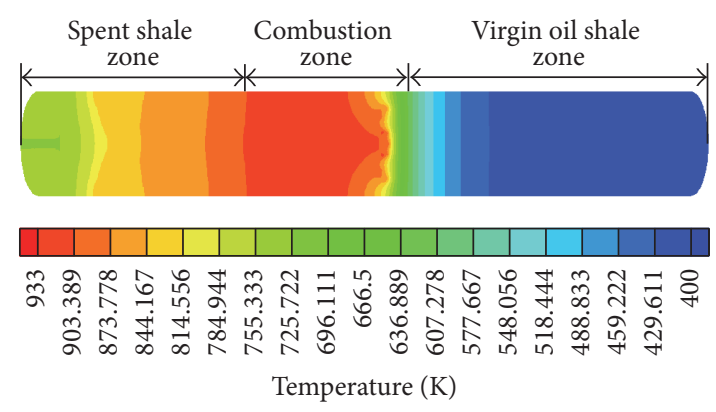

(f) $t=600 \mathrm{~min}$

Figure 5: Contours of temperature at different times.

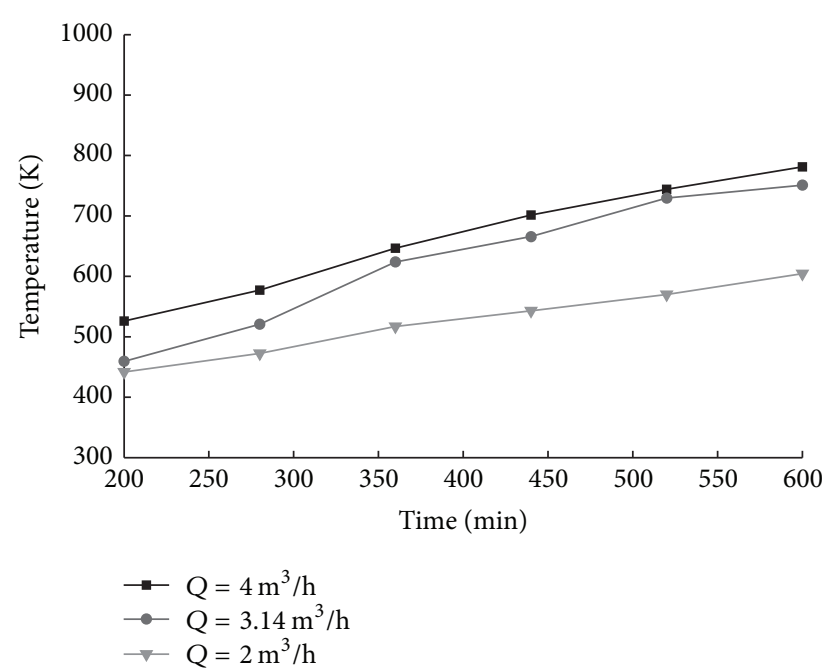

Figure 6: The average temperature of oil shale for different gas injection rate.

are simulated; $4 \mathrm{~m}^{3} / \mathrm{h}$ is the base case. Figure 6 shows the average temperature of oil shale in the combustion tube; it is obvious that higher gas injection rate leads to higher average temperature. By increasing gas injection rate, more oxygen was offered for combustion reactions. In other words, the thermal front was well sustained. So, it is no surprise that there is more energy released through the reactions in the case of higher injection rate, and the average temperature in the tube was higher than that in the low injection rate cases. At the same time, the higher injection rate leads to quicker movement of reaction fronts. In order to represent the sensitivity of a few parameters clearly, the oil production rate $P_{\text {oil }}$ is introduced. The parameter $P_{\text {oil }}$ is defined as the ratio of oil produced by pyrolysis to oil content measured by the Fisher method. There are more pyrolysis reactions occurring in the case of high injection rate; thus the oil production rate was higher as shown in Figure 7. With the continuing increase of flow rate, the average temperature of oil shale and the oil production rate could not keep on increasing. That is because the oil content of oil shale is limited and the amount of heat generation of coke combustion is limited also.

3.2.2. Effect of Permeability. Permeability also plays a significant role in the ISC process. In order to investigate the effects of permeability on average temperature and oil production rate, two additional runs with $5000 \mathrm{md}$ and 1000 md have been compared with the 10000 md of base 


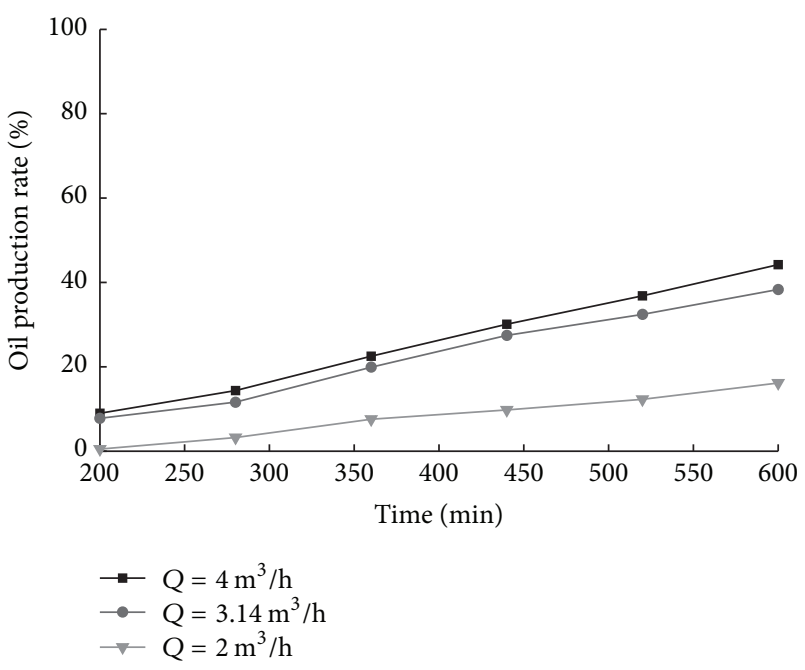

FIGURE 7: Oil production rate for different gas injection rate.

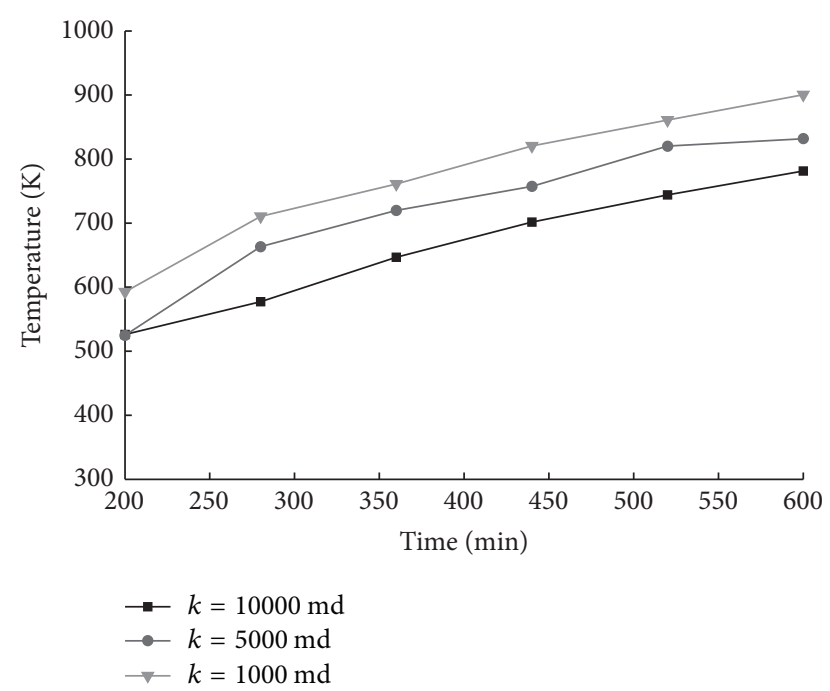

FIgURE 8: The average temperature of oil shale for different permeability.

case. Figure 8 shows the average temperature of oil shale, with different permeability. The average temperature of oil shale is higher in the case of low permeability. It is clear that oil in high permeable porous reservoir will be mobilized and flow downstream as the temperature increases to the suitable value. Otherwise oil in low permeability reservoir will hardly be mobilized compared with high permeability, so the combustion peak lasts longer. In other words, coke reacts with oxygen completely, releasing more heat than high permeability case. In Figure 9, a high oil production rate was obtained in the case of high permeability, which is due to the high flow rate. The effects of permeability on average temperature and oil production rate in Figures 8 and 9 are consistent with the results obtained in Shojaiepour's research [23].

3.2.3. Effect of Initial Oil Content. The initial oil content of oil shale $\left(P_{c}\right.$ represents the oil weight content in the oil shale) also

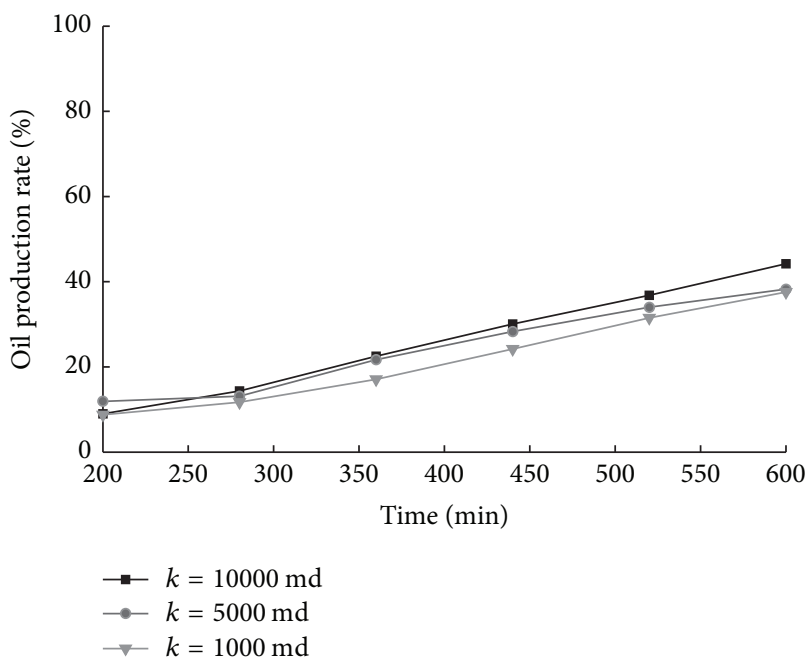

FiguRE 9: Oil production rate for different permeability.

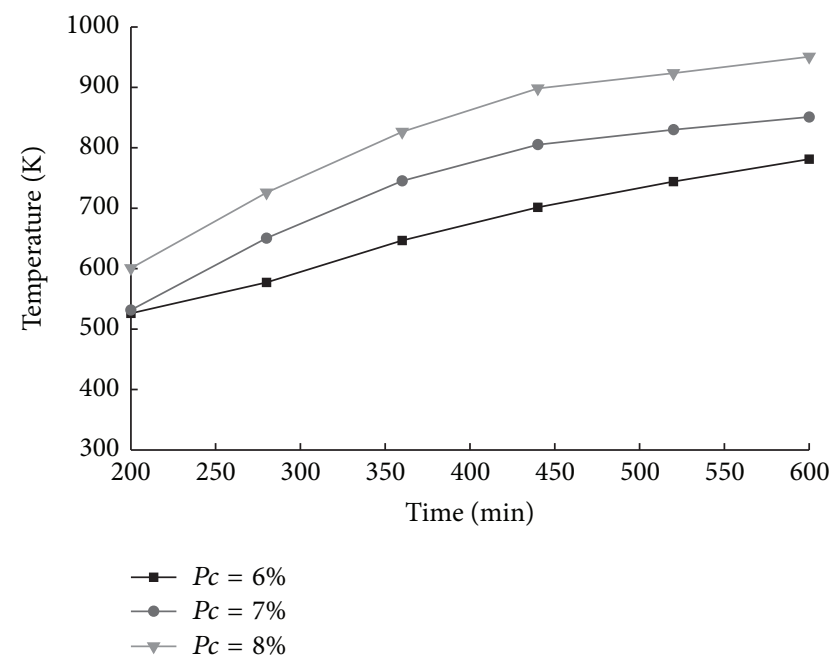

FIGURE 10: The average temperature of oil shale for different initial oil content.

has a great effect on ISC simulation. Varied oil contents of oil shale represent the diversity of underground oil shale layers. In this study, the average temperature and the oil production rate were shown in Figures 10 and 11, respectively. The initial oil content of base case is $6 \%$, and those of other cases are $7 \%$ and $8 \%$. The average temperature of oil shale is higher in the case of higher initial oil content. It is obvious that as initial oil content increases, the oxidation reaction rate increases, which also causes more heat releasing. As the fluid viscosity is significantly affected by temperature, the oil production rate is high in the case of high initial oil content as shown in Figure 11.

3.2.4. Effect of the Injected Oxygen Content. In the experiments [21], the content of injected oxygen can be adjusted. Figure 12 shows the average temperature of oil shale in the combustion tube for different injected oxygen content. The 


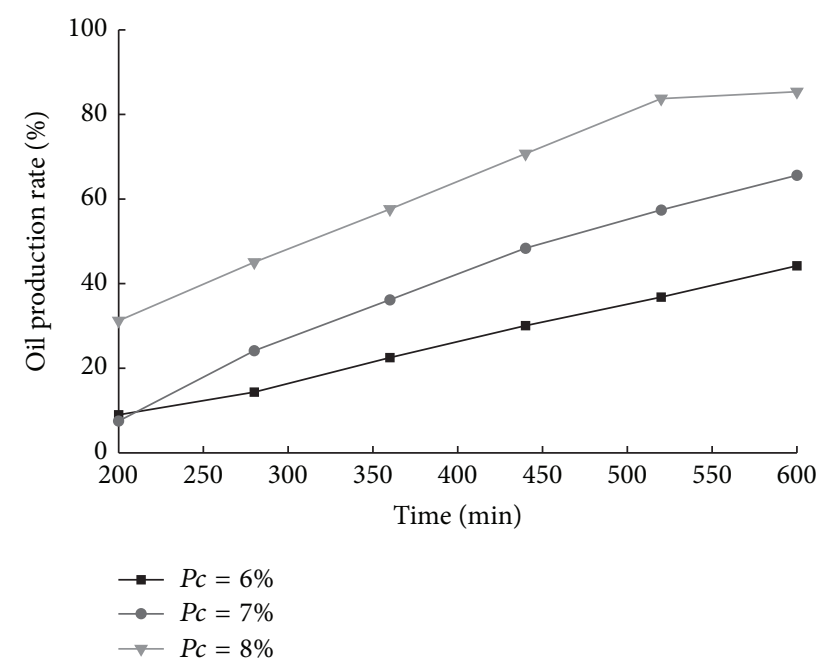

FIGURE 11: Oil production rate for different initial oil content.

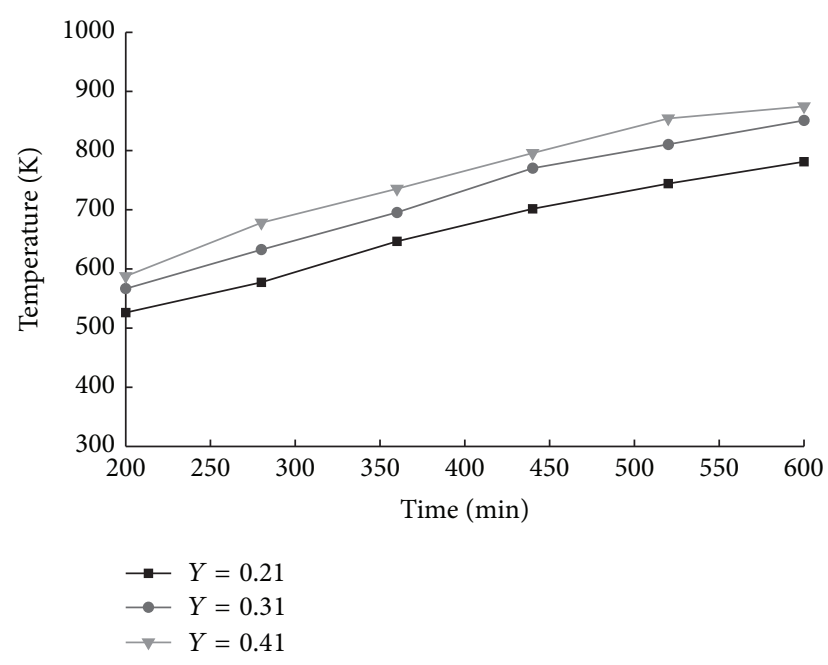

FIGURE 12: The average temperature of oil shale for different injected oxygen content.

oxygen content of the base case is 0.21 , and those of others are 0.31 and 0.41 . As shown in Figure 12, average temperature of the base case is lower than the other cases. The high oxygen content not only plays a positive role in average temperature for ISC process, but also affects the oil production rate. Due to the high injected oxygen content, the combustion reactions in the tube run completely and large amount of heat is released to increase the combustion temperature. On the other hand, amount of oxygen is needed to sustain the combustion front during ISC process. Due to the high oxygen content, more coke is consumed in the reaction; thus the combustion front is widened. In Figure 13, the oil production rate is higher in the case of high oxygen content. This shows that more oxygen content at the entrance causes higher oil production rate and shortened combustion time.

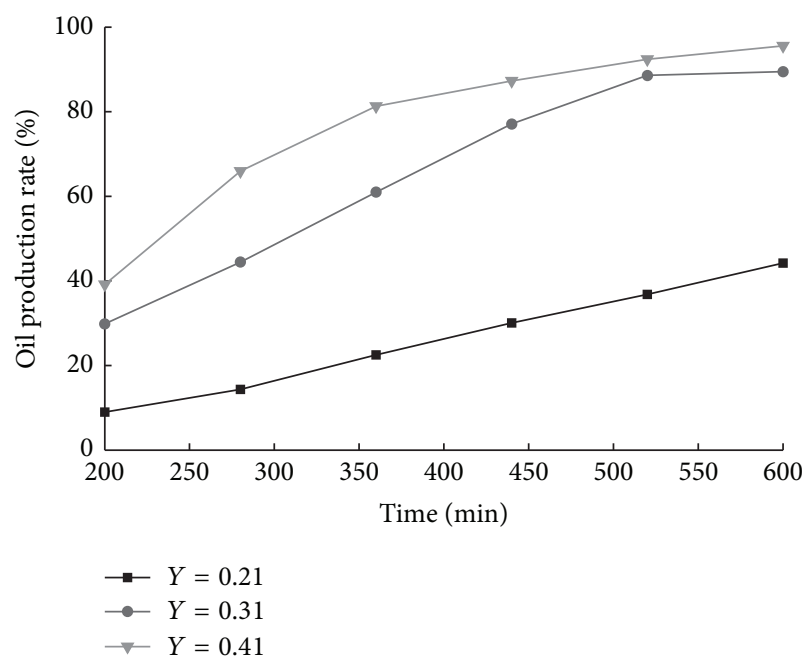

FIGURE 13: Oil production rate for different injected oxygen content.

\section{Conclusions}

In this research, in situ combustion process of oil shale was studied. We simulated the ISC process in a horizontal combustion tube within which reactions occur from the toe to heel. Four key parameters, gas injection rate, permeability, initial oil content, and injected oxygen content, were changed, and their effects were investigated and analyzed. The results of this study can provide a foundation for future researches relating to high production efficiency method to enhance oil shale recovery. The following conclusions are drawn:

(1) It is verified that this numerical study is suitable for simulating ISC process of oil shale.

(2) The combustion reactions can be simplified as two oxidation reactions. The simulation results based on the simplified oxidation reactions are consistent with the experimental results [21].

(3) The frontal velocity $0.2114 \mathrm{~cm} / \mathrm{min}$ fairly matches the experimental datum which is $0.2333 \mathrm{~cm} / \mathrm{min}$ [21]. It shows that the simplified model is accurate enough to simulate the in situ combustion.

(4) The developed User's Defined Functions provide a feasible tool for modeling oil shale combustion.

(5) Increasing the gas injection rate and the injected oxygen content can enhance the oil production rate. High permeability and high initial oil content also play the active role in ISC process.

\section{Nomenclature}

E: Activation energy $(\mathrm{J} / \mathrm{mol})$

$M$ : Molecular weight $(\mathrm{kg} / \mathrm{kmol})$

$P$ : Pressure $(\mathrm{Pa})$

$R$ : Ideal gas constant $(\mathrm{J} / \mathrm{mol} \mathrm{K})$

$T$ : Temperature $(\mathrm{K})$

$Y$ : Molar fraction

c: Specific heat capacity $(\mathrm{J} / \mathrm{kg} \mathrm{K})$ 


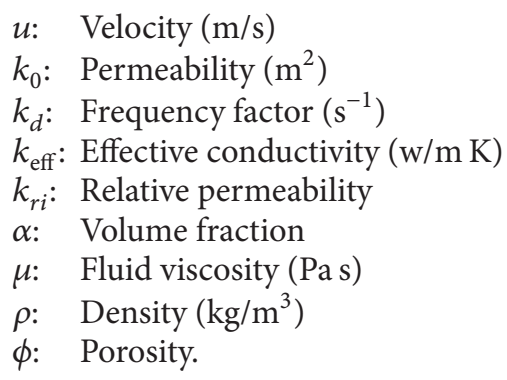

\section{Conflicts of Interest}

The authors declare that they have no conflicts of interest.

\section{Acknowledgments}

This work was supported by the National Cooperative Innovation Project on Chinese Potential Oil and Gas Resources (Grant no. OSR-03-05) and the National Natural Science Foundation of China (no. J1310022).

\section{References}

[1] Y. Fan, L. J. Durlofsky, and H. A. Tchelepi, "Numerical simulation of the in-situ upgrading of oil shale," SPE Journal, vol. 15, no. 2, pp. 368-381, 2010.

[2] J. H. Bauman, K. H. Chung, M. R. Gani, and M. D. Deo, "Modeling of the in-situ production of oil from oil shale," in ACS Symposium Series, vol. 1032, pp. 135-146, Oxford University Press, 2010.

[3] D. R. Isakov, D. K. Nurgaliev, D. A. Shaposhnikov, and O. S. Chernova, "Features of mathematical modeling of in-situ combustion for production of high-viscosity crude oil and natural bitumens," Chemistry and Technology of Fuels and Oils, vol. 50, no. 6, pp. 579-583, 2015.

[4] E. Knaus, J. Killen, K. Biglarbigi, and P. Crawford, "An overview of oil shale resources," in ACS Symposium Series, vol. 1032, pp. 3-20, Oxford University Press, 2010.

[5] Y.-H. Sun, F.-T. Bai, X.-S. Lü et al., "A novel energy-efficient pyrolysis process: self-pyrolysis of oil shale triggered by topochemical heat in a horizontal fixed bed," Scientific Reports, vol. 5, pp. 8290-8297, 2015.

[6] P. M. Crawford and J. C. Killen, "New challenges and directions in oil shale development technologies," in ACS Symposium Series, vol. 1032, pp. 21-60, Oxford University Press, 2010.

[7] I. A. Nesterov, A. A. Shapiro, and E. H. Stenby, "Numerical analysis of a one-dimensional multicomponent model of the in-situ combustion process," Journal of Petroleum Science and Engineering, vol. 106, pp. 46-61, 2013.

[8] M. S. K. Youtsos, E. Mastorakos, and R. S. Cant, "Numerical simulation of thermal and reaction fronts for oil shale upgrading," Chemical Engineering Science, vol. 94, pp. 200-213, 2013.

[9] P. R. Kapadia, M. S. Kallos, and I. D. Gates, "A review of pyrolysis, aquathermolysis, and oxidation of Athabasca bitumen," Fuel Processing Technology, vol. 131, pp. 270-289, 2015.

[10] M. S. K. Youtsos and E. Mastorakos, "Numerical simulation of thermal and reaction waves for in situ combustion in hydrocarbon reservoirs," Fuel, vol. 108, pp. 780-792, 2013.

[11] D. Srinivasareddy and G. S. Kumar, "A numerical study on phase behavior effects in enhanced oil recovery by in situ combustion,"
Petroleum Science and Technology, vol. 33, no. 3, pp. 353-362, 2015.

[12] Z. Liu, K. Jessen, and T. T. Tsotsis, "Optimization of insitu combustion processes: a parameter space study towards reducing the CO2 emissions," Chemical Engineering Science, vol. 66, no. 12, pp. 2723-2733, 2011.

[13] D. Marchesin, N. K. Gargar, A. A. Mailybaev, and J. Bruining, "Recovery of light oil by air injection," in Proceedings of the 14th European Conference on the Mathematics of Oil Recovery, Sicily, Italy, September 2014.

[14] A. A. Mailybaev, J. Bruining, and D. Marchesin, "Analysis of in situ combustion of oil with pyrolysis and vaporization," Combustion and Flame, vol. 158, no. 6, pp. 1097-1108, 2011.

[15] N. K. Gargar, A. A. Mailybaev, D. Marchesin, and H. Bruining, "Numerical simulation of recovery of light oil by medium temperature oxidation in porous media," in Proceedings of the 8th Annual Conference on Multiphysiscs Simulation, COMSOL, pp. 10-12, Milan, Italy, 2012.

[16] A. Lapene, M. F. Martins, G. Debenest, M. Quintard, and S. Salvador, "Numerical simulation of oil shale combustion in a fixed bed: modelling and chemical aspects," in Proceedings of the Eurotherm Seminar No. 81 Reactive Heat Transfer in Porous Media, pp. 4-6, Albi, France, June 2007.

[17] S. Yang, J. Zhang, Q. Yang, and Y. Qian, "Development of an integrated oil shale refinery with retorting gas steam reforming for hydrogen production," Energy and Fuels, vol. 28, no. 8, pp. 5557-5564, 2014.

[18] X. Lü, Y. Sun, T. Lu, F. Bai, and M. Viljanen, "An efficient and general analytical approach to modelling pyrolysis kinetics of oil shale," Fuel, vol. 135, pp. 182-187, 2014.

[19] K. Nazridoust and G. Ahmadi, "Computational modeling of methane hydrate dissociation in a sandstone core," Chemical Engineering Science, vol. 62, no. 22, pp. 6155-6177, 2007.

[20] G. Chapiro, A. A. Mailybaev, A. J. de Souza, D. Marchesin, and J. Bruining, "Asymptotic approximation of long-time solution for low-temperature filtration combustion," Computational Geosciences, vol. 16, no. 3, pp. 799-808, 2012.

[21] M. V. Kök, G. Guner, and S. Bagc, "Application of EOR techniques for oil shale fields (in-situ combustion approach)," Oil Shale, vol. 25, no. 2, pp. 217-225, 2008.

[22] N. K. Gargar, A. A. Mailybaev, D. Marchesin, and H. Bruining, "Effects of water on light oil recovery by air injection," Fuel, vol. 137, pp. 200-210, 2014.

[23] M. Shojaiepour, R. Kharrat, M. Shojaiepour, and A. Hashemi, "Experimental and simulation study of in-situ combustion process in carbonate fractured porous media," Journal of the Japan Petroleum Institute, vol. 57, no. 5, pp. 208-215, 2014. 

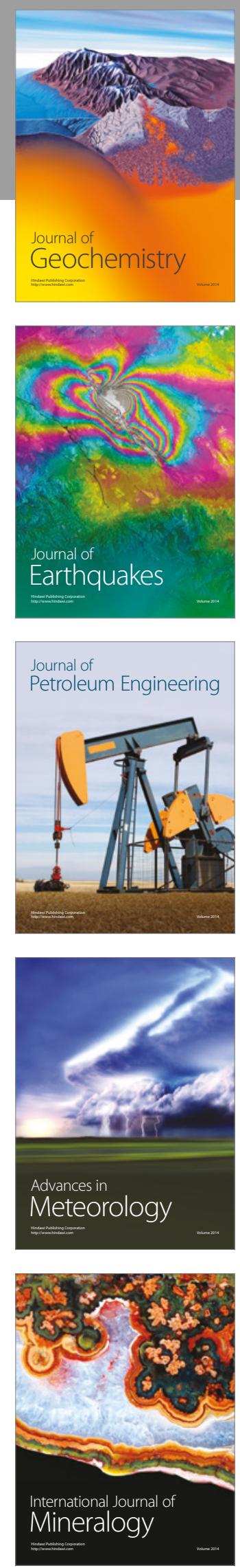


Submit your manuscripts at

https://www.hindawi.com
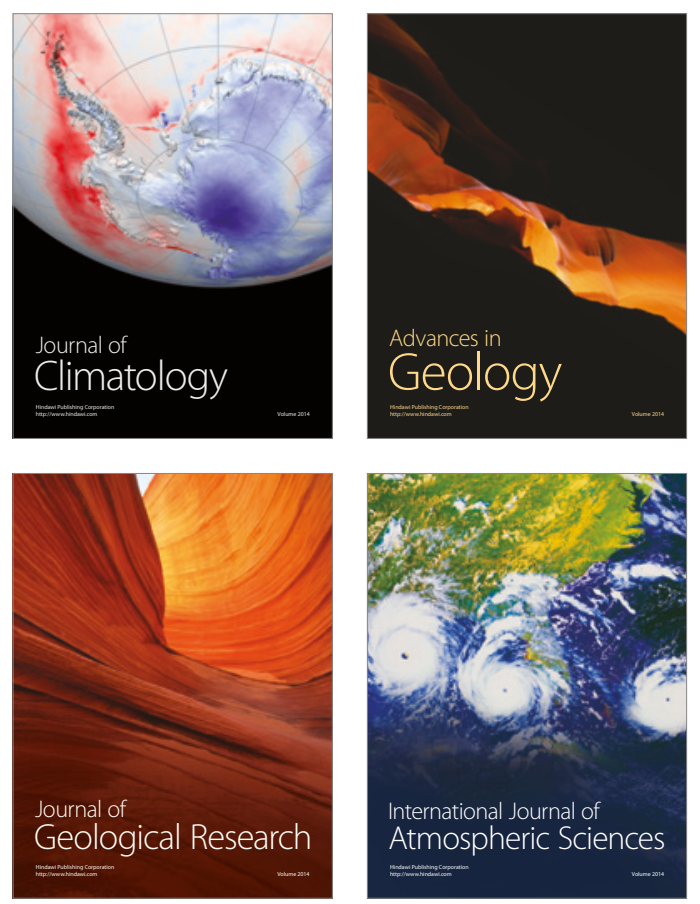

The Scientific

World Journal
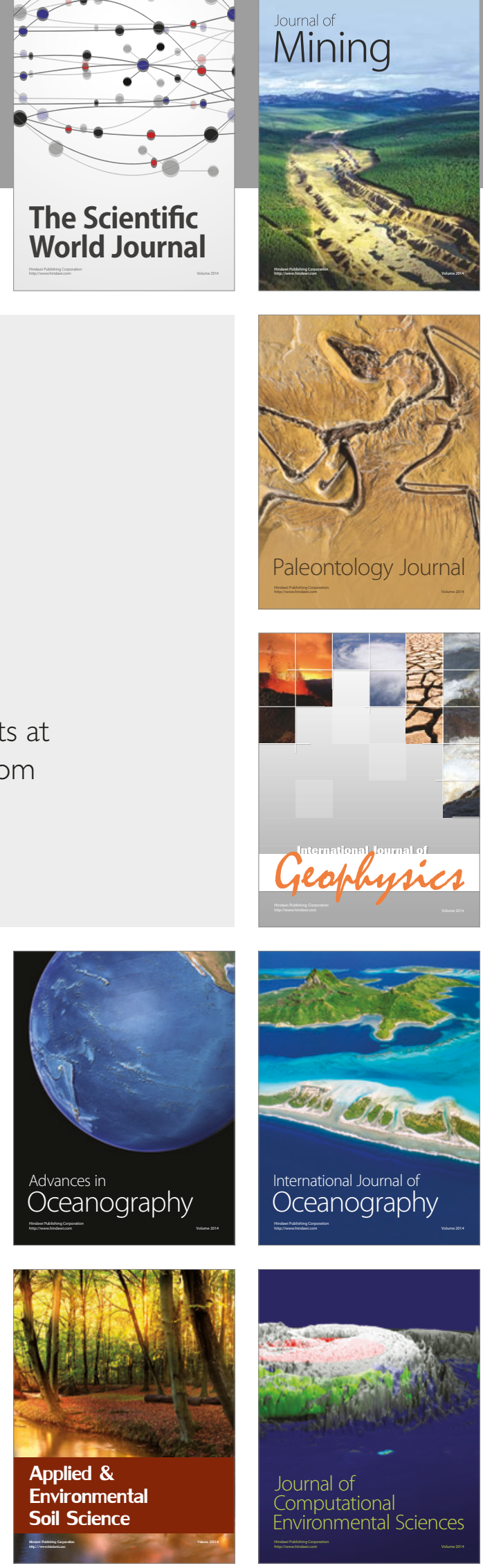